\title{
Methodological Comparisons of Absorptive and Transport Fine Root Production, Mortality and Decomposition in A Loblolly Pine Plantation Forest
}

Xuefeng Li ( $\sim$ Ixf.victor@gmail.com )

North Carolina State University https://orcid.org/0000-0002-7783-9942

Xingbo Zheng

Institute of Applied Ecology

Quanlai Zhou

Institute of Applied Ecology

Michael Gavazzi

Eastern Forest Environmental Threat Assessment Center

Yanlong Shan

Beihua University

Steve McNulty

Eastern Forest Environmental Threat Assessment Center

John S. King

North Carolina State University

\section{Research Article}

Keywords: Fine root, production, mortality, decomposition, method, loblolly pine plantation

Posted Date: June 18th, 2021

DOl: https://doi.org/10.21203/rs.3.rs-553243/v1

License: (9) This work is licensed under a Creative Commons Attribution 4.0 International License.

Read Full License 
1 Methodological comparisons of absorptive and transport fine root production, mortality and decomposition

2 in a loblolly pine plantation forest

3 Xuefeng Li ${ }^{1,4 *}$, Xingbo Zheng ${ }^{1}$, Quanlai Zhou ${ }^{1}$, Michael Gavazzi ${ }^{2}$, Yanlong Shan ${ }^{3}$, Steven McNulty ${ }^{2}$, John S. King ${ }^{4}$,

$4 \quad{ }^{1}$ Institute of Applied Ecology, Chinese Academy of Sciences, Shenyang City, 110016 China

$5 \quad{ }^{2}$ USDA Forest Service, Eastern Forest Environmental Threat Assessment Center, Raleigh, NC, United States

$6 \quad 3$ Department of Forestry, Beihua University, Jilin City, 132013 China

$7{ }^{4}$ Department of Forestry and Environmental Resources, North Carolina State University, Raleigh, NC, 27695,

$8 \quad$ United States

$9 \quad *$ Corresponding author: lxf.victor@gmail.com; Tel (919) 376-7856

\section{Abstract}

Background and aims Fine roots can be functionally classified into an absorptive fine root pool (AFR) and a transport fine root pool (TFR) and their production, mortality and decomposition play a critical role in forest soil carbon (C) cycling. Different methods give significant estimates. However, how methodological difference affects

14 AFT and TFR production, mortality, and decomposition estimates remains unclear, impeding us to accurately construct soil $\mathrm{C}$ budgets.

Methods We used dynamic-flow model, a model combining measurements of litterbags and soil cores, and

17 balanced-hybrid model, a model combining measurements of minirhizotrons and soil cores, to quantify these fine root estimates in a managed loblolly pine forest. for both AFRs and TFRs. Annual production, mortality, and decomposition were comparable between AFRs and TFRs when measured using the dynamic-flow model but significantly higher for AFRs than for TFRs when measured using the balanced-hybrid model. Annual production, mortality and decomposition estimates using the balanced-hybrid model were $75 \%, 71 \%$ and $69 \%$ higher than those using the dynamic-flow model $(P<0.05$ for all),

24 respectively, for AFRs, but 12\%, 6\% and 5\% higher than those using the dynamic-flow model $(P>0.05$ for all $)$, 25 respectively, for TFRs. Model test showed that the balanced-hybrid model had greater estimation accuracy than the 
dynamic-flow model. Lower AFR estimates using the dynamic-flow model appeared to result from the underestimated AFR mass loss rate induced by the litterbag method.

Conclusions Methodological difference had a more significant impact on AFR estimates than on TFR estimates.

29 These results have important implications for better quantifying the most dynamic fraction of fine root system and understanding soil C cycling.

31 Key words Fine root $\cdot$ production $\cdot \operatorname{mortality} \cdot$ decomposition $\cdot$ method $\cdot$ loblolly pine plantation

\section{Introduction}

Fine roots are the most physiologically active component of the below-ground plant system (McCormack et al. 2015). Studies conducted at the ecosystem scale showed that fine root growth consumed up to $63 \%$ of forests' net primary production (Vogt 1991; Litton et al. 2007). Fine root mortality and decomposition accounted for nearly half of organic carbon (C) input into the soil and around 10\% of soil heterotrophic $\mathrm{C}$ emission, respectively (Ding et al. 2019; Li et al. 2020a). Thus, accurate measurements of fine root production, mortality and decomposition in forests are critical for quantifying forest $\mathrm{C}$ allocation and cycling and parameterizing climate change models (Woodward and Osborne 2000; Ghimire et al. 2016).

The conventional ingrowth core and soil core methods, which are low cost and ready-to-use, had been extensively applied to assess fine root production and mortality (Vogt et al. 1998; Brunner et al. 2013; Addo-Danso

42 et al. 2016). However, these methods are not reliable because the amount of fine roots died and decomposed during 43 sampling intervals cannot be reasonably quantified (Osawa and Aizawa 2012). To overcome this weakness, several

44 improved ingrowth core/soil core models have been developed in which fine root biomass and necromass dynamics

45 and mass loss rate were integrated into mass balance equations (Osawa and Aizawa 2012; Li et al. 2013; Li and

46 Lange 2015). Dynamic-flow model is a new improved soil core model (Li and Lange 2015). In theory, it has greater

47 estimation accuracy than other modified soil coring methods because fine root decomposition rate is assumed to 48 decrease over time rather than remain constant (Santantonio and Grace 1987; Osawa and Aizawa 2012). This

49 assumption has been supported by the facts that the labile and recalcitrant components in fine roots have different

50 mass loss rates, with the former being depleted much faster than the latter (Fan and Guo 2010; Lin et al. 2011).

51 Minirhizotrons allow to monitor the growth and death of individual fine roots continuously while overcoming the 
52 cofounding of spatiotemporal variation (McCormack et al. 2014, 2015). The balanced-hybrid model is an improved 53 minirhizotron-based model to quantify fine root production, mortality and decomposition by combining

54 measurements of soil cores and minirhizotrons with mass balance equations (Li et al. 2020a).

55 Fine roots have been traditionally defined as distal roots with diameters $<2 \mathrm{~mm}$. Recent studies have shown that 56 the hierarchical root system is morphologically, chemically and functionally heterogeneous and can be partitioned 57 into two pools: absorptive fine roots (AFRs) and transport fine roots (TFRs) (Pregitzer et al. 2002; McCormack et 58 al. 2015). AFRs represent the most distal roots with relatively higher $\mathrm{N}$ concentration and shorter lifespan and 59 involve primarily in the absorption of soil resources. In contrast, TFRs occur higher in the branching hierarchy with 60 relatively lower $\mathrm{N}$ concentration and longer lifespan and function mainly as resource transportation and storage.

61 Studying fine roots as two functional pools instead of a single diameter-based pool enables a more accurate 62 characterization of fine root processes (Sun et al. 2012). It has been recommended that multiple methods should be 63 used to yield more reliable fine root estimates (Hendricks et al. 2006; Addo-Danso et al. 2016). However, AFR and 64 TFR production, mortality and decomposition have not been jointly quantified using dynamic-flow and balanced65 hybrid models, leading to significant uncertainties in forest fine root C budgets. Loblolly pine (Pinus taeda $\mathrm{L}$.) 66 plantation forests cover 11 million hectares, accounting for 50\% of the standing pine volume in the southern USA 67 (Wear and Greis 2012). It has been estimated that over 1 billion seedlings are planted annually (Wear and Greis 68 2012). An improved understanding of AFR and TFR dynamics in loblolly pine plantation forests is critical for 69 developing silvicultural and rotation strategies to increase C sequestration capacity.

70 In this study, we used the soil core method, litterbags, and minirhizotrons to assess biomass and necromass 71 dynamics, mass loss pattern and growth and death rates of AFRs and TFRs in a managed loblolly pine forest. The 72 objectives were to 1) use both the dynamic-flow model and the balanced-hybrid model to quantify AFR and TFR 73 production, mortality, and decomposition in this forest, 2) assess to what extent methodological difference affects 74 AFR and TFR estimates and 3) determine which method is more reliable.

75

\section{Materials and methods}

77 Study site 
The study was conducted in a commercially managed loblolly pine ( $P$. taeda $\mathrm{L}$.) forest $\left(35^{\circ} 48^{\prime} \mathrm{N} 76^{\circ} 40^{\prime} \mathrm{W}\right)$ located in the lower coastal plain of Washington County, North Carolina, USA. Mean annual precipitation and temperature for the period $2011-2017$ were $1320 \mathrm{~mm}$ and $12.2{ }^{\circ} \mathrm{C}$, respectively. The topography of the area is flat $(<5 \mathrm{~m}$ above sea level) and on a Belhaven series histosol soil (loamy mixed dysic thermic terric Haplosaprists). The study area was harvested of trees and ditched/drained in the late 19th to the early 20th century before being converted to a commercial pine plantation. The forest was fertilized with nitrogen and phosphorus at the time of planting and midrotation. The soil $\mathrm{C}$ and nitrogen concentrations at $20 \mathrm{~cm}$ depth were $26 \%$ and $1.0 \%$, respectively. The mean canopy height, diameter at the breast height, and stand age during the study period were approximately $24 \mathrm{~m}, 33 \mathrm{~cm}$, and 23 years, respectively. For a full site description, refer to Noormets et al. (2010). Three plots, about $5 \mathrm{~m} \times 9 \mathrm{~m}$ for each and $100 \mathrm{~m}$ to $800 \mathrm{~m}$ apart, were established at random in the plantation in 2013 . Only loblolly pine fine roots were studied as they accounted for over $90 \%$ of total fine root mass in this forest.

\section{Fine root biomass and necromass measurements}

Fine root biomass and necromass were determined using the soil coring method. The number of soil cores required at both plot and stand-level was calculated using the methods in Bartlett et al. (2001) and Dornbush et al. (2002). In each plot, 8 cylindrical soil cores $(3.0 \mathrm{~cm}$ diameter, $30 \mathrm{~cm}$ depth) were randomly collected on 6 sampling occasions from April 2016 to April 2017, forming 5 soil sampling intervals (Li et al. 2020a). Previous study showed that over $90 \%$ of fine roots were distributed in $0-30 \mathrm{~cm}$ soil layer. Collected soil cores were rinsed with clean tap water through a $0.5 \mathrm{~mm}$ mesh sieve to isolate roots. We only studied loblolly pine fine roots as they accounted for over $95 \%$ of total fine root mass. Loblolly pine fine roots with light color and intact stele and periderm were regarded as live roots, while those with dark color and damaged stele and periderm were dead ones. In this study, AFRs represented the first and second-order roots, while TFRs were third-order roots and higher with diameter $<2 \mathrm{~mm}$. Live and dead AFRs and TFRs were separated according to the procedures described in Li et al. (2020b). All fine roots were dried at $50{ }^{\circ} \mathrm{C}$ to a constant weight and weighed. The measurements of biomass and necromass in the soil cores were scaled to $\mathrm{g} \mathrm{m}^{-2}$ over a $0-0.30 \mathrm{~m}$ soil layer. 
AFR and TFR mass loss rates were assessed using litterbags. To provide input parameters for dynamic-flow model, we used four types of fine roots including live and dead AFRs and TFRs as the decomposing substrate in in situ

107 decomposition experiments. Each litterbag $(20 \mathrm{~cm} \times 3.5 \mathrm{~cm}, 0.05 \mathrm{~mm}$ mesh) was evenly filled with about $0.15 \mathrm{~g}$ fine root materials and inserted vertically into a $0-20 \mathrm{~cm}$ of soil. This experimental design intended to have fine root materials distributed evenly in different soil layers. The decomposition experiment began on 8 August 2016. The litterbags were collected after 65, 105 and 310 days of incubation. On each sampling occasion, three litterbags of each of the four root types were retrieved from each plot. Roots from the litterbags were rinsed with clear tap water, carefully sorted, dried at $50{ }^{\circ} \mathrm{C}$ to a constant weight and then weighed.

AFR and TFR production, mortality and decomposition were determined using the dynamic-flow model (Li and Lange 2015; $\mathrm{Li}$ et al. 2020b). Interval $i$ was any given soil coring interval $(1 \leq i)$ (year). $\mathrm{G}_{\mathrm{I}-\mathrm{i}}$ and $\mathrm{G}_{\mathrm{II}-\mathrm{i}}$ were the fine roots that died before the start of interval $i$ and in interval $i$, respectively. The mass loss patterns of $\mathrm{G}_{\mathrm{I}-\mathrm{i}}$ and $\mathrm{G}_{\mathrm{II}-\mathrm{i}}$ were simulated by the litterbag method with dead and live roots used as decomposing substrates, respectively.

Fine root mass loss pattern was simulated using an exponential equation with only two parameters:

$$
y(t)=y_{0} e^{(-\lambda / k)\left(1-e^{-k t}\right)}
$$

where $y_{(\mathrm{t})}$ and $y_{0}$ are root mass at time $t$ (year) and the start, respectively. The two parameters $\lambda\left(\right.$ year $^{-1}$ ) and $k$ $\left(\right.$ year $^{-1}$ ) were calculated based on the fine root mass remaining in litterbags collected on all sampling occasions using and decreases over time. and decomposition $\left(d_{\mathrm{i}}\right)$ in interval $i$ were calculated by the following equations,

$$
g_{\mathrm{i}}=B_{\mathrm{i}}(0)-B_{\mathrm{i}}+m_{\mathrm{i}}
$$

$$
d_{\mathrm{i}}=m_{\mathrm{i}}-\left(N_{\mathrm{i}}-N_{\mathrm{i}}(0)\right)
$$




$$
N_{\mathrm{I}-\mathrm{i}}=N_{\mathrm{i}}(0) \mathrm{e}^{\left(-\lambda_{\mathrm{I}-\mathrm{i}} / k_{\mathrm{I}-\mathrm{i}}\right)\left(1-e^{-k_{\mathrm{I}-\mathrm{i}} T}\right)}
$$

$$
N_{\mathrm{II}-\mathrm{i}}=N_{\mathrm{i}}-N_{\mathrm{I}-\mathrm{i}}
$$

$$
m_{\mathrm{i}}=\mu_{\mathrm{i}} \mathrm{T}
$$

where $B_{\mathrm{i}}(0)$ and $B_{\mathrm{i}}$ represented the fine root biomass in soil cores sampled at the start and the end of interval $i$, respectively, $N_{\mathrm{i}}(0)$ and $N_{\mathrm{i}}$ represented the fine root necromass at the start and the end of interval $I$, and $N_{\mathrm{III}-\mathrm{i}}$ and $N_{\mathrm{I}-\mathrm{i}}$ were the mass remaining of $\mathrm{G}_{\mathrm{II}-\mathrm{i}}$ and $\mathrm{G}_{\mathrm{I}-\mathrm{i}}$ at end of interval $i$, respectively. T was time length of interval $i$.

$$
\mu_{\mathrm{i}}=k_{\mathrm{II}-\mathrm{i}} N_{\mathrm{II}-\mathrm{i}} \frac{e^{-\left(\lambda_{\mathrm{II}-\mathrm{i}} / k_{\mathrm{II}-\mathrm{i}}\right)} e^{-k_{\mathrm{II}-\mathrm{i}} T}}{E_{1}\left(\left(\lambda_{\mathrm{II}-\mathrm{i}} / k_{\mathrm{II}-\mathrm{i}}\right) e^{-k_{\mathrm{II}-\mathrm{i}} T}\right)-E_{1}\left(\lambda_{\mathrm{II}-\mathrm{i}} / k_{\mathrm{II}-\mathrm{i}}\right)}
$$

where $E_{1}(z)=\int_{z}^{\infty} \frac{e^{-x}}{x} d x$

was an exponential integral function (Abramowitz and Stegun, 1964, ch. 6).

$B_{\mathrm{i}}(0), B_{\mathrm{i}}, N_{\mathrm{i}}, N_{\mathrm{i}}(0), N_{\mathrm{II}-\mathrm{i}}$, and $N_{\mathrm{I}-\mathrm{i}}$ had the unit $\mathrm{g} \cdot \mathrm{m}^{-2} . \lambda_{\mathrm{I}-\mathrm{i}}, k_{\mathrm{I}-\mathrm{i}}, \lambda_{\mathrm{II}-\mathrm{i}}$, and $k_{\mathrm{II}-\mathrm{i}}$ were decomposition parameters for $\mathrm{G}_{\mathrm{I}-\mathrm{i}}$ and $\mathrm{G}_{\mathrm{II}-\mathrm{i}}$, respectively, calculated using Eq.1. $B_{\mathrm{i}}(0), B_{\mathrm{i}}, N_{\mathrm{i}}$ and $N_{\mathrm{i}}(0)$ were measured in the soil cores, $N_{\mathrm{II}-\mathrm{i}}$ was calculated by Eq. (4) and $m_{\mathrm{i}}=\mu_{\mathrm{i}} T$. Thus, $g_{\mathrm{i}}$ and $d_{\mathrm{i}}$ were calculated by Eqs. 2 and 3, respectively. $g_{\mathrm{i}}, m_{\mathrm{i}}$ and $d_{\mathrm{i}}$ have the unit $\mathrm{g} \cdot \mathrm{m}^{-}$ ${ }^{2}$ year $^{-1}$.

144 A total of 18 acrylic tubes ( $80 \mathrm{~cm}$ long, $6 \mathrm{~cm}$ outer diameter) were installed in 2013 at a $45^{\circ}$ angle to a vertical soil 145 depth of $50 \mathrm{~cm}$ in the three plots (5 to 8 tubes per plot). We took root images on 17 sampling dates from late April 1462016 through late April 2017, which co-occurred with soil coring (Li et al. 2020a). Images were collected using a

147 Bartz digital camera with the image capture software BTC I-CAP (Bartz Technology Corp., Carpinteria, CA, USA).

148 Fine root length and diameter were quantified by analyzing the images with WinRHIZO software (Regents

149 Instruments Inc., Quebec, Canada). AFR and TFR length production, mortality and standing length density (mean root length per unit root image area) were calculated based on the image analysis. An AFR or TFR was counted as dead if its diameter shriveled to half the original diameter, it showed signs of deterioration including fragmenting 
152 and ectomycorrhizal fungal mantle detachment, or it was consumed by soil animals; otherwise, roots were

153 considered as living (McCormack et al. 2014; Kou et al. 2018).

156 Fine root length production $\left(\mathrm{LP}_{\mathrm{i}}, \mathrm{m} \mathrm{m}^{-2}\right.$ image $)$ and mortality $\left(\mathrm{LM}_{\mathrm{i}}, \mathrm{m} \mathrm{m}^{-2}\right.$ image $)$ in a given soil coring interval $i$

157 were estimated from minirhizotron image analysis. $\mathrm{LP}_{\mathrm{i}}$ and $\mathrm{LM}_{\mathrm{i}}$ were calculated as the length of fine roots that were 158 produced and died in interval $i$, respectively (Kou et al. 2018).

159 Fine root turnover $\left(\mathrm{TR}_{\mathrm{i}}\right)$ and death rates $\left(\mathrm{DR}_{\mathrm{i}}\right)$ in the interval were calculated as

161

$\mathrm{DR}_{\mathrm{i}}=\mathrm{LM}_{\mathrm{i}} / \mathrm{SL}_{\mathrm{i}}$ et al. 2020a).

$$
g_{\mathrm{i}}=\mathrm{B}_{\mathrm{i}}(0) \times \mathrm{TR}_{\mathrm{i}} \quad(10)
$$

$$
m_{\mathrm{i}}=\mathrm{B}_{\mathrm{i}}(0) \times \mathrm{DR}_{\mathrm{i}}
$$

172 The efficacy of the models for estimating the production, mortality, and decomposition was tested by comparing the

173 predicted with the measured AFR and TFR biomass in July using a subset of data not used for model

174 parameterization. Smaller differences between predicted and measured biomass values mean greater estimation 
175 accuracy. The predicted AFR and TFR biomass in July were calculated according to the procedures described in 176 Hendrick and Pregitzer (1993) and Hendricks et al. (2006).

178 Statistical analysis

179 The plots were considered as replicates $(\mathrm{n}=3)$, and data collected (sub-replicates) within the same plot were

180 averaged before performing statistical analysis. One-way ANOVA or paired $t$-test was used to assess the differences

181 in means of measured fine root variables. The data were log-transformed to normalize variances among the

182 estimates of the two models before analysis when necessary. All data were analyzed using the SPSS statistical

183 software (version 17.0; IBM Corporation, Somers, NY 10589, USA).

\section{3. Results}

Biomass and necromass

AFR and TFR biomass showed the same temporal pattern, with the highest values in July and the lowest values in

187 January, while AFR and TFR necromass did not show evident peak and trough values during the whole study period

188 (Fig. 1). AFRs had significantly lower mean biomass than TFRs $\left(67.8 \pm 5.3\right.$ vs. $\left.88.7 \pm 2.9 \mathrm{~g} \mathrm{~m}^{-2}\right)(P<0.05)$. The mean

189 necromass of AFRs was lower than that of TFRs (41.2 \pm 2.8 vs. $\left.50.4 \pm 5.2 \mathrm{~g} \mathrm{~m}^{-2}\right)$, but the difference was not

190 significant $(P>0.05)$.

192 Mass loss rate

193 Live AFR substrates had significantly higher percent mass remaining than live TFR substrates at the late

194 decomposing stage, but dead AFR and TFR substrates had comparable percent mass remaining during the whole

195 study period (Fig. 2). All live root substrates decomposed significantly faster than dead root substrates (Fig. 2).

197 Temporal changes in fine root estimates 
Temporal changes in fine root production, mortality and decomposition rates were generally the same between the two models, with greater production in warmer months and greater mortality and decomposition occurring in cooler months (Fig. 3). Production, mortality, and decomposition rates using dynamic-flow model were comparable

201 between AFRs and TFRs at all intervals. In contrast, production, mortality, and decomposition rates using the balanced-hybrid model were significantly higher for AFRs than for TFRs in most intervals (Fig. 3). AFR production, mortality and decomposition rates using the dynamic-flow model were significantly lower than those using the

204 balanced-hybrid model in most intervals, while TFR production, mortality and decomposition rates were not significantly different between the two models in all intervals (Fig. 3).

Annual production, mortality, and decomposition were comparable between AFRs and TFRs in dynamic-flow model estimation but significantly higher for AFRs than for TFRs in balanced-hybrid model estimation (Fig. 4). Annual AFR production, mortality, and decomposition estimates using the balanced-hybrid model were $75 \%, 71 \%$, and $69 \%$ higher than those using the dynamic-flow model ( $P<0.05$ for all), respectively (Fig. 4). By contrast,

212 annual TFR production, mortality, and decomposition estimates using the balanced-hybrid model were $12 \%, 6 \%$, 213 and 5\% higher than those using the dynamic-flow model ( $P>0.1$ for all), respectively (Fig. 4). Annual fine root (i. e. AFR + TFR) production, mortality, and decomposition were $119 \pm 9,133 \pm 7$, and $124 \pm 11 \mathrm{~g} \mathrm{~m}^{-2}$, respectively,

215 when using the dynamic-flow model and $172 \pm 11,185 \pm 12$, and $171 \pm 14 \mathrm{~g} \mathrm{~m}^{-2}$, respectively, when measured using 216 the balanced-hybrid model. the balanced-hybrid model, respectively, while the measured TFR biomass in July was $19 \%$ and $11 \%$ higher than

221 that estimated by the dynamic-flow model and the balanced-hybrid model, respectively, indicating that the balanced222 hybrid model is more accurate than the dynamic-flow model.

\section{Discussion}


224 Fine root dynamics in forests have been increasingly studied by functional groups. However, most of the existing 225 studies were two-dimensional minirhizotron analysis (McCormack et al. 2015; Kou et al. 2018) and did not include

226 measurements of AFR and TFR biomass and necromass dynamics due to great labor and time input (Li et al.

227 2020b). Failing to assess the biomass and necromass dynamics impedes us to characterize soil C flux dynamics

228 through AFR and TFR growth, death and decay. In this managed loblolly pine forest, AFRs had significantly lower

229 biomass than TFRs but made comparable or even significantly greater contributions to total fine root production,

230 mortality and decomposition than TFRs did, demonstrating that three-dimensional, function-based study is essential to accurately quantify fine root $\mathrm{C}$ budget.

Different methods yielded divergent fine root estimates, but all these methodological comparisons were diameter-based rather than function-based estimates (Hendricks et al. 2006; Osawa and Aizawa 2012; Li and Lange 2015). This knowledge gap has hindered us to better identify the strengths and weaknesses of each method and characterize the $\mathrm{C}$ allocation pattern within the root system. Our study for the first time used two types of models, a

236 litterbag-based model and a minirhizotron-based model, to assess AFR and TFR production, mortality, and 237 decomposition. AFR estimates were significantly more responsive to methodological difference than TFR estimates.

238 Thus, methodological difference impact must be taken into account when assessing AFR and TFR dynamics.

Model test showed that the balanced-hybrid model had greater estimation accuracy than the dynamic-flow model. This can be explained by the inherent differences between them. In the balanced-hybrid model, the relative production and mortality rates at the tube-soil interface are assumed to be representative of those in bulk soil. This assumption has been proved to be very likely in previous studies (Hendrick and Pregitzer 1993; Hendricks et al.

244 root mortality rate remains constant in a certain interval and fine root mass loss pattern in litterbags is the same as 245 that in bulk soil. Both are unrealistic as the mortality rate has been found to vary greatly among seasons 246 (McCormack et al. 2014; Kou et al. 2018) and the decomposer community compositions in litterbags are different 247 from those in natural soil (Bokhorst and Wardle 2013; Li et al. 2015; Beidler and Pritchard 2017). As a result, there 248 would be greater errors in fine root estimates using the dynamic-flow model than using the balanced-hybrid model.

249 The significantly smaller AFR estimates of the dynamic-flow model compared to the balanced-hybrid model can 250 be ascribed to the underestimated AFR mass loss rate by litterbags. In existing litterbag-based models including the 
251 dynamics-flow model (Osawa and Aizawa 2012; Li and Lange 2015), mortality is positively related to the

252 production and decomposition and fine root mass loss rate is the dominant determinant in mortality estimation.

253 Higher fine root mass loss rate results in greater mortality estimate and therefore greater production and

254 decomposition estimates. Since both models used the same biomass and necromass data, lower mass loss rate was

255 the only cause for the smaller AFR estimates in the dynamic-flow model estimation. Whether litterbags significantly

256 underestimate TFR mass loss rate is still unclear. But one thing is certain: litterbag studies misrepresent fine root

257 mass loss rate by using unrepresentative root materials (Kunkle et al. 2009; Fan and Guo 2010; Sun et al. 2018) and

258 disrupting the interactions between roots, soil fauna and soil microbes (Koide et al. 2011; Li et al. 2015; Beidler and

259 Pritchard 2017; Moore et al. 2020).

260 The balanced-hybrid model can continuously track the growth and death of individual AFRs and TFRs while 261 maintaining the rhizosphere associations (McCormack et al. 2015; Beidler and Pritchard 2017), which makes it

262 effective in comparing fine root estimates between functional groups. By contrast, the capacity of the dynamic-flow

263 model in distinguishing AFR and TFR estimates has been severely undermined by its inherent weaknesses. First,

264 hyphal connections with AFRs and TFRs were cut off when processing the root samples in the decomposition

265 experiment, representing a major departure from in situ conditions (Koide et al. 2011; Sun et al. 2018). Second, AFR

266 and TFR litterbags were placed at different locations in forest soils, which results in a cofounding of spatiotemporal

267 variation (i. e. the effect of variances in soil environmental conditions on the mass loss rate could cover the inherent

268 difference in decomposability between AFRs and TFRs). For this reason, the higher estimates for AFRs than for

269 TFRs in the balanced-hybrid estimation generally reflected the real situation, while the comparable estimates

270 between AFRs and TFRs in the dynamic-flow model estimation was most likely an error of the model.

\section{Conclusion}

273 The balanced-hybrid has a greater estimation accuracy than the dynamic-flow model and differences between the

274 two models did not significantly affect TFR estimates but significantly affected AFR estimates. Thus, the

275 methodological difference must be considered to accurately characterize AFR and TFR dynamics and to quantify

276 fine root $\mathrm{C}$ fluxes in forests. 
278 Acknowledgments We thank Jordan Luff, Wen Lin, and Yuan Fang for their help with analyzing the minirhizotron

279 images and processing the samples. Primary supports were provided by USDA NIFA (Multi-agency A.5 Carbon

280 Cycle Science Program) award 2014-67003-22068 and National Natural Science Foundation of China.

281

282 Declaration of Competing Interest

283

284

The authors declare that they have no conflict of interest.

285

286

287

288

Addo-Danso SD, Presscott CE, Smith AR (2016) Methods for estimating root biomass and production in forest and woodland ecosystem carbon studies: A review. For Ecol Manage 359: 332-351.

Bartlett JE, Kotrlic JW, Higgins CC (2001) Organizational Research: Determining the Appropriate Sample Size in Survey Research. ITLPJ 19: 43-50.

Beidler KV, Pritchard SG (2017) Maintaining connectivity: Understanding the role of root order and mycelial networks in fine root decomposition of woody plants. Plant Soil 420: 19-36.

Brunner I, Bakker MR, Bjork RG, Hirano Y, Lukac M, Aranda X et al. (2013) Fine-root turnover rates of European forests revisited: an analysis of data from sequential coring and ingrowth cores. Plant and Soil 362: 357-372.

Ding Y, Leppälammi-Kujansuu J, Helmisaari H (2019) Fine root longevity and below-and aboveground litter production in a boreal Betula pendula forest. For Ecol Manage 431: 17-25. 
nutrient retention in the soil. Oecologia 163: 509-515.

302 Ghimire B, Riley WJ, Koven CD, Mu M, Randerson JT (2016) Representing leaf and root physiological

303 traits in CLM improves global carbon and nitrogen cycling predictions. J Adv Model Earth Syst 8: 598-613.

304 Hendrick RL, Pregitzer KS (1993) The dynamics of fine root length, biomass, and nitrogen content in two northern 305 hardwood ecosystems. Can J For Res 23: 2507-2520.

306 Hendricks JJ, Hendrick RL, Wilson CA, Mitchell RJ, Pecot SD, Guo DL (2006) Assessing the patterns and controls of fine root dynamics: an empirical test and methodological review. J Ecol 94: 40-57.

Hertel D, Leuschner C (2002) A comparison of four different fine root production estimates with ecosystem carbon balance data in a Fagus-Quercus mixed forest. Plant Soil 239: 237-251.

Koide RT, Fernandez CW, Peoples MS (2011) Can ectomycorrhizal colonization of Pinus resinosa roots affect their decomposition? New Phytol 191: 508- 514.

312 Kou L, Jiang L, Fu X, Dai X, Wang H, Li S (2018) Nitrogen deposition increases root production and turnover but slows root decomposition in Pinus elliottii plantations. New Phytol 218: 1450- 1461.

314 Kunkle JM, Walters MB, Kobe RK (2009) Senescence-related changes in nitrogen in fine roots:

315 mass loss affects estimation. Tree Physiol 29: 715-723.

316 Li A, Fahey TJ, Pawlowska TE, Fisk MC, Burtis J (2015) Fine root decomposition, nutrient mobilization and fungal 317 communities in a pine forest ecosystem. Soil Biol. Biochem 83:76-83.

Li X, Lange H (2015) A modified soil coring method for measuring fine root production, mortality and decomposition in forests. Soil Biol Biochem 91: 192-199.

Li X, Minick KJ, Li T, Williamson JC, Gavazzi M, McNulty S, King JS (2020a) An improved method for measuring total fine root decomposition in plantation forests combing minirhizotrons with soil coring. Tree Physiol. 40: 1466-1473. 
Li X, Zhu J, Lange H, Han S (2013) A modified ingrowth core method for measuring fine root production, mortality and decomposition in forests. Tree Physiol 33: 18-25.

Lin C, Yang Y, Guo J, Chen G, Xie J (2011) Fine root decomposition of evergreen broadleaved and coniferous tree species in mid-subtropical China: dynamics of dry mass, nutrient and organic fractions. Plant Soil 338: 311327.

Litton CM, Raich JW, Ryan MG (2007) Carbon allocation in forest ecosystems. Glob Chang Biol 13: 2089-2109.

McCormack ML, Adams TS, Smithwick EAH, Eissenstat DM (2014) Variability in root production, phenology, and turnover rate among 12 temperate tree species. Ecology 95: 2224-2235.

McCormack LM, Dickie IA, Eissenstat DM et al. (2015) Redefining fine roots improves understanding of belowground contributions to terrestrial biosphere processes. New Phytol 207: 505-518.

Moore JAM, Sulman BN, Mayes MA, Patterson CM, Classen AT (2020) Plant roots stimulate the decomposition of complex, but not simple, soil carbon. Funct Ecol 34:899-910. fluxes to drought in a coastal plain loblolly pine forest. Glob Chang Biol 16: 272-287. using litter bag experiments and soil core techniques. Plant Soil 355: 167-181. of nine North American trees. Ecol Monog 72:293-309.

344 Santantonio D, Grace JC (1987) Estimating fine-root production and turnover from biomass and decomposition data: a compartment-flow model. Can J For Res 17(8): 900-908. 
346

347

348

349

350

351

352

353

354

355

356

357

358

359

360

361

362

363

364

365

366

367

7

8

59

60

61

Sun T, Hobbie SE, Berg B, Zhang H, Wang Q, Wang Z, Hättenschwiler S (2018) Contrasting dynamics and trait controls in first-order root compared with leaf litter decomposition. PNAS 115: 10392-10397.

Sun JJ, Gu J, Wang Z (2012) Discrepancy in fine root turnover estimates between diameter- based and branch-order-based approaches: a case study in two temperate tree species. J For Res 23: 575-581.

Vogt KA (1991) Carbon budgets of temperate forest ecosystems. Tree Physiol 9: 69-86.

Vogt KA, Vogt DJ, Bloomfield J (1998) Analysis of some direct and indirect methods for estimating root biomass and production of forests at an ecosystem level. Plant Soil 200: 71-89.

Wear DN, Greis JG, The Southern Forest Futures Project: Summary Report; USDA Forest Service Southern Research Station: Washington, DC, USA, 2012; p. 54.

Woodward FI, Osborne CP (2000) The representation of root processes in models addressing the responses of vegetation to global change. New Phytol 147: 223-232.

62 
373 Fig.1 Absorptive (AFR) and transport (TFR) fine root biomass and necromass dynamics ( $\mathrm{g} \mathrm{m}^{-2}$ for the $0-0.30 \mathrm{~m}$ soil

374 depth; $\mathrm{n}=3$; mean \pm SE).

375 Note: AFR biomass and necromass have been reported. We use these values for the purpose of comparison.

377 Fig. 2 Mass loss patterns of live and dead absorptive (AFR) and transport (TFR) fine root substrates measured using 378 litterbags in a managed loblolly pine forest $(n=3$; mean \pm SE; different letters stand for significant difference in 379 means, $P<0.05)$.

Fig. 3 Temporal changes in production, mortality and decomposition estimates of absorptive (AFR) and transport

382 (TFR) fine roots using balanced-hybrid model (BH) and dynamic-flow model (DF) in a managed loblolly pine 383 plantation forest $(\mathrm{n}=3$; mean $\pm \mathrm{SE})$. Different letters stand for significant difference in means $(P<0.05)$.

384 Note: AFR production, mortality and decomposition estimates using balanced-hybrid model have been reported. We use these values for the purpose of comparison.

387 Fig. 4 Annual absorptive (AFR) and transport (TFR) fine root production, mortality and decomposition measured 388 using balanced-hybrid model (BH) and dynamic-flow model (DF) in a managed loblolly pine plantation forest $(\mathrm{n}=$ 3893 ; mean $\pm \mathrm{SE})$. Different letters stand for significant difference in means $(P<0.05)$. 
Figures

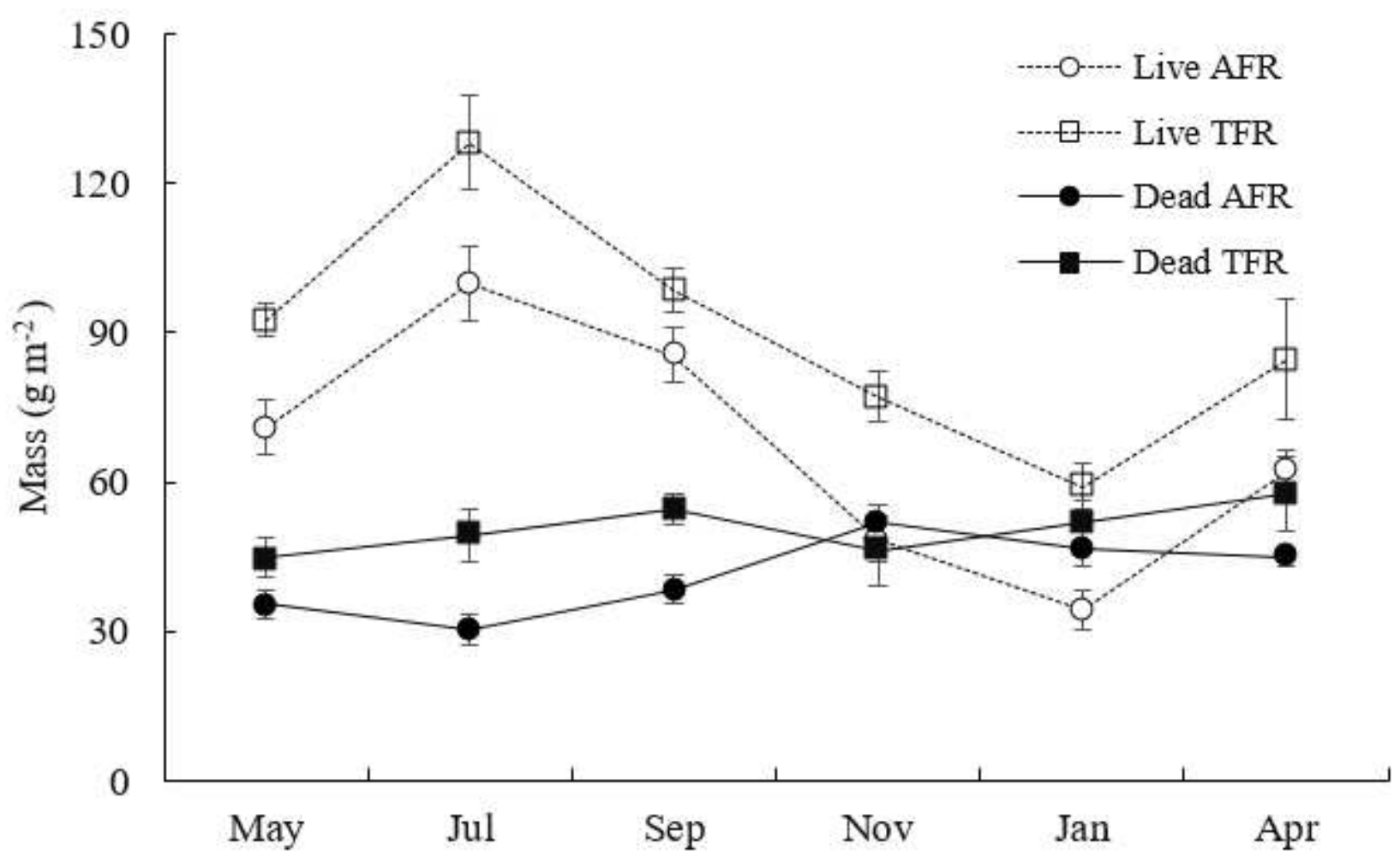

Figure 1

Absorptive (AFR) and transport (TFR) fine root biomass and necromass dynamics ( $\mathrm{g} \mathrm{m}-2$ for the $0-0.30 \mathrm{~m}$ soil depth; $n=3$; mean $\pm S E$ ). Note: AFR biomass and necromass have been reported. We use these values for the purpose of comparison. 


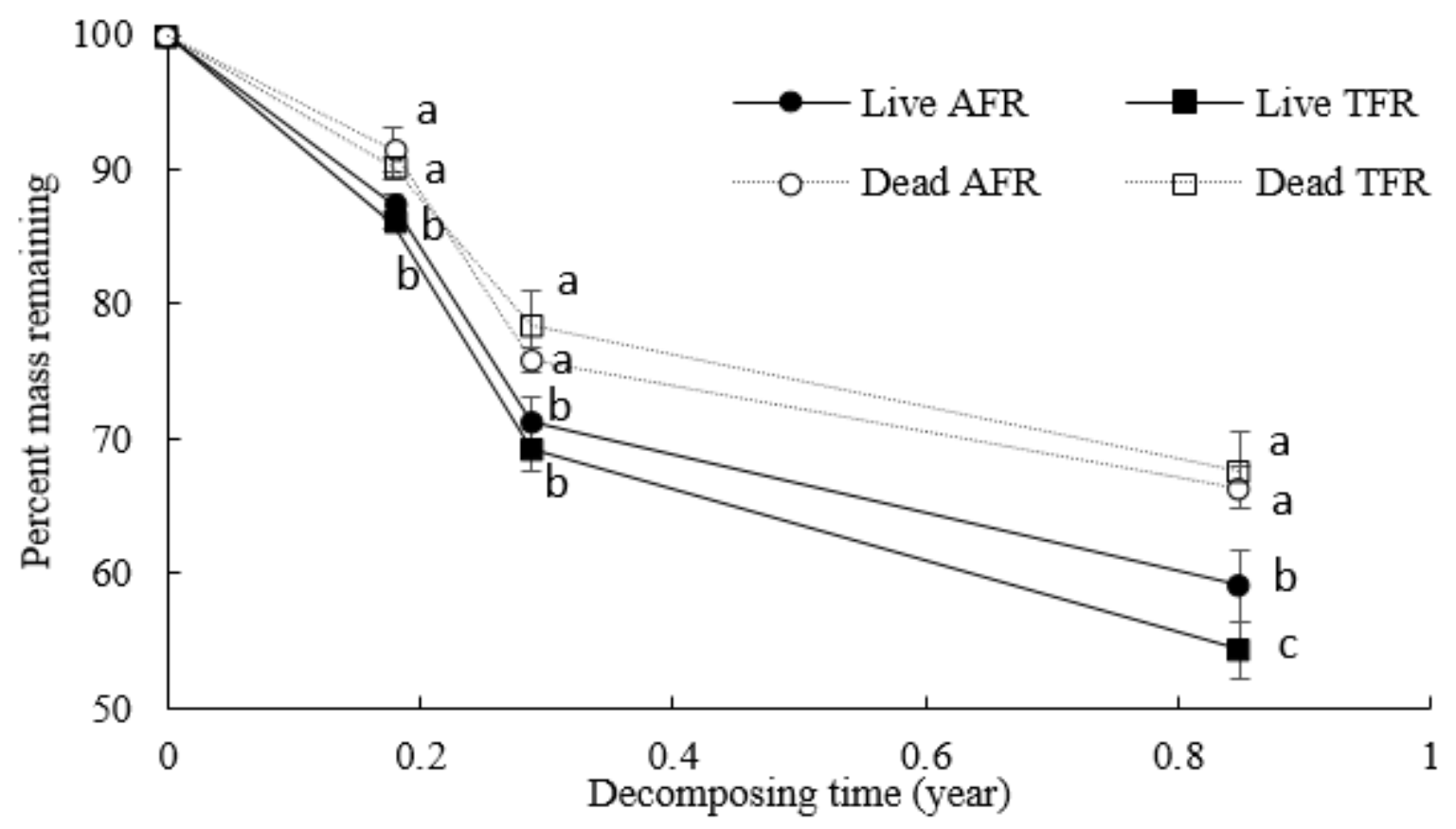

Figure 2

Mass loss patterns of live and dead absorptive (AFR) and transport (TFR) fine root substrates measured using litterbags in a managed loblolly pine forest $(n=3$; mean $\pm S E$; different letters stand for significant difference in means, $\mathrm{P}<0.05)$. 

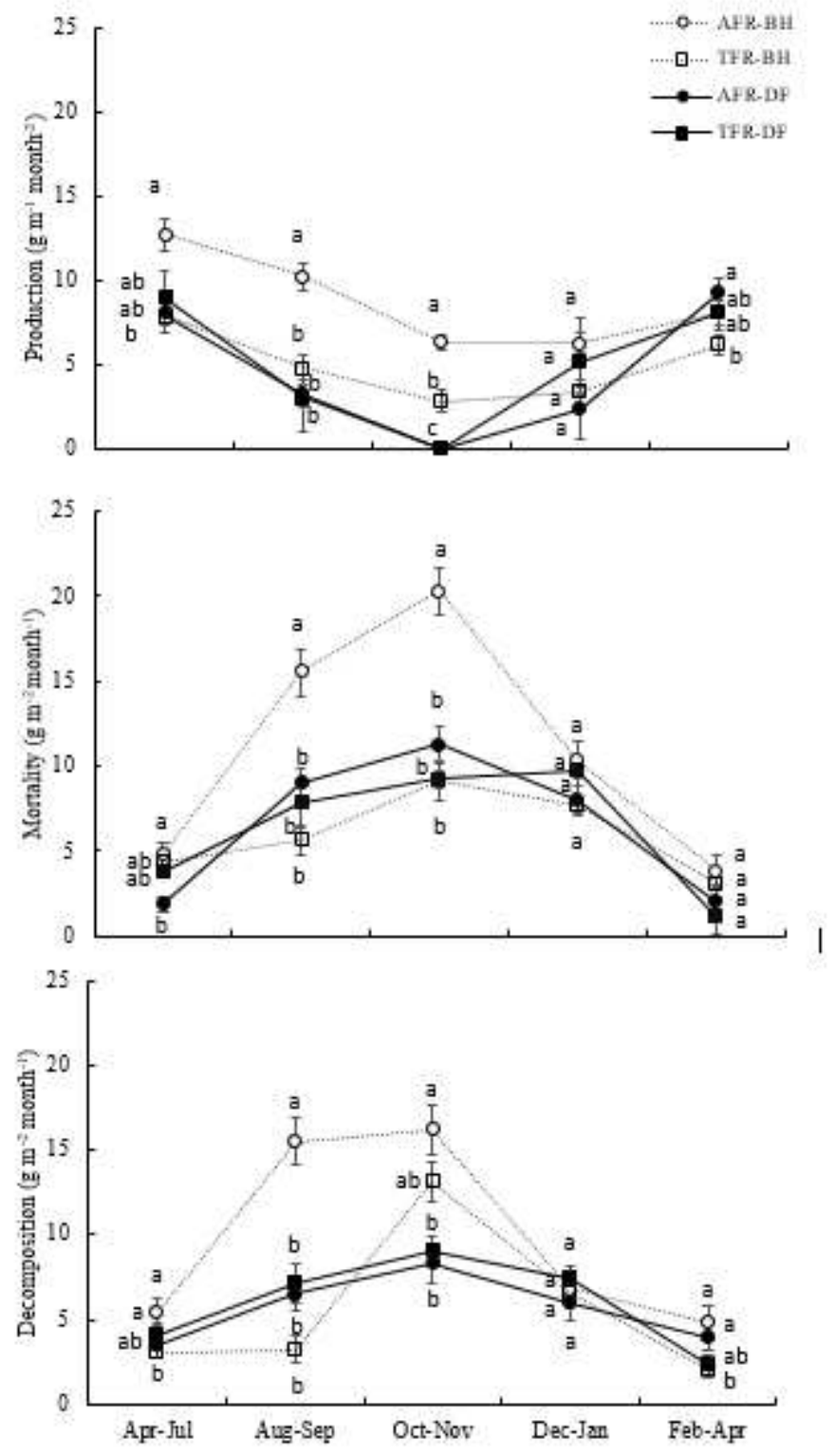

\section{Figure 3}

Temporal changes in production, mortality and decomposition estimates of absorptive (AFR) and transport (TFR) fine roots using balanced-hybrid model (BH) and dynamic-flow model (DF) in a managed loblolly pine plantation forest $(n=3$; mean $\pm S E)$. Different letters stand for significant difference in means $(P<0.05)$. Note: AFR production, mortality and decomposition estimates using balanced-hybrid model have been reported. We use these values for the purpose of comparison. 

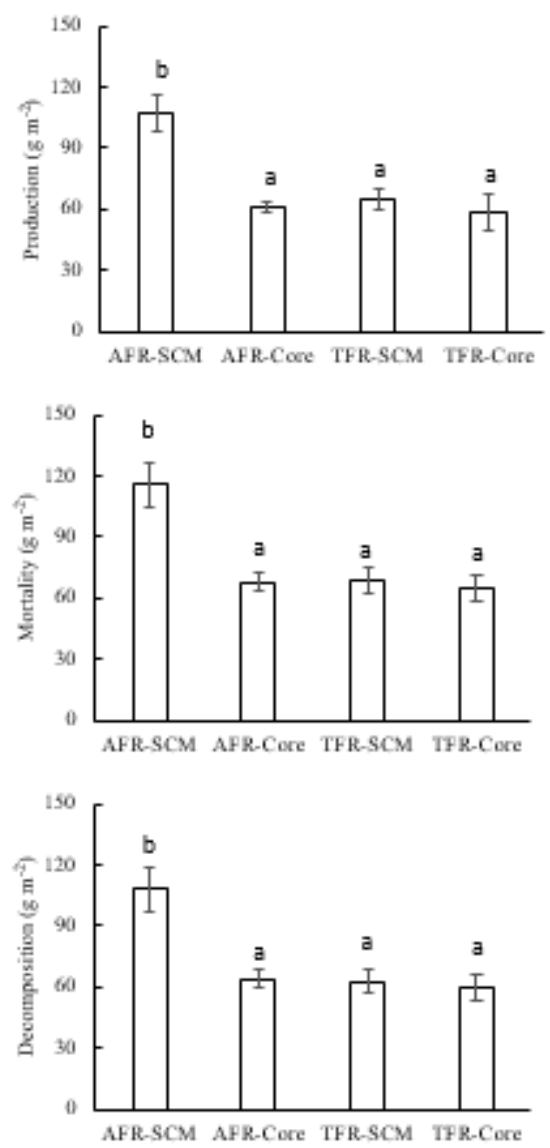

Figure 4

Annual absorptive (AFR) and transport (TFR) fine root production, mortality and decomposition measured using balanced-hybrid model (BH) and dynamic-flow model (DF) in a managed loblolly pine plantation forest $(n=3$; mean $\pm S E)$. Different letters stand for significant difference in means $(P<0.05)$. 